\title{
Ionotropic and Metabotropic Mechanisms of Allosteric Modulation of $\alpha 7$ Nicotinic Receptor Intracellular Calcium $\$$
}

\author{
Justin R. King, Aman Ullah, Ellen Bak, M. Saleet Jafri, and Nadine Kabbani \\ Interdisciplinary Program in Neuroscience (J.R.K., M.S.J., N.K.) and School of Systems Biology (A.U., E.B., M.S.J., N.K.), George \\ Mason University, Fairfax, Virginia
}

Received December 11, 2017; accepted March 23, 2018

\section{ABSTRACT}

The pharmacological targeting of the $\alpha 7$ nicotinic acetylcholine receptor $(\alpha 7)$ is a promising strategy in the development of new drugs for neurologic diseases. Because $\alpha 7$ receptors regulate cellular calcium, we investigated how the prototypical type IIpositive allosteric modulator PNU120596 affects $\alpha 7$-mediated calcium signaling. Live imaging experiments show that PNU120596 augments ryanodine receptor-driven calciuminduced calcium release (CICR), inositol-induced calcium release (IICR), and phospholipase C activation by the $\alpha 7$ receptor. Both influx of calcium through the $\alpha 7$ nicotinic acetylcholine receptor (nAChR) channel as well as the binding of intracellular $\mathrm{G}$ proteins were involved in the effect of PNU120596 on intracellular calcium. This is evidenced by the findings that chelation of

\section{Introduction}

Nicotinic acetylcholine receptors (nAChRs) are prototype cys-loop receptor channels with the ability to undergo ligandassociated structural changes that translate chemical signals to electrical information (Changeux, 2010). Of the nine different $\mathrm{nAChR}$ subunits identified in the mammalian brain, the homomeric $\alpha 7 \mathrm{nAChR}(\alpha 7)$ is one of the most abundant, present in both neuronal and non-neuronal cells and expressed in regions of the brain such as the hippocampus and cortex. The $\alpha 7$ receptors play an important role in signaling that underlies short-term changes in presynaptic neurotransmitter release, as well as postsynaptic dendritic plasticity (Halff et al., 2014). Signaling through $\alpha 7$ can modulate learning, memory, and pain responses and support neuroprotection through an inhibition of inflammation (Shytle et al., 2004; Freitas et al., 2013a, b; King et al., 2017). The $\alpha 7 \mathrm{nAChR}$ is thus an attractive drug target in the treatment of human diseases such as Alzheimer's disease, schizophrenia, and human immunodeficiency virus-associated neuroinflammatory disease (Wang et al., 2003; Bencherif et al., 2011; Deutsch et al., 2013; GuerraÁlvarez et al., 2015).

https://doi.org/10.1124/mol.117.111401.

S This article has supplemental material available at molpharm. aspetjournals.org. extracellular calcium, expression of $\alpha 7_{\mathrm{D} 44 \mathrm{~A}}$ or $\alpha 7_{345-348 \mathrm{~A}}$ mutant subunits, or blockade of calcium store release compromised the ability of PNU120596 to increase intracellular calcium transients generated by $\alpha 7$ ligand activation. Spatiotemporal stochastic modeling of calcium transient responses corroborates these results and indicates that $\alpha 7$ receptor activation enables calcium microdomains locally and to lesser extent in the distant cytosol. From the model, allosteric modulation of the receptor activates CICR locally via ryanodine receptors and augments IICR through enhanced calcium influx due to prolonged $\alpha 7 \mathrm{nAChR}$ opening. These findings provide a new mechanistic framework for understanding the effect of $\alpha 7$ receptor allosteric modulation on both local and global calcium dynamics.

ABBREVIATIONS: ACh, acetylcholine; ANOVA, analysis of variance; Bgtx, $\alpha$-bungarotoxin; CICR, calcium-induced calcium release; ER, endoplasmic reticulum; fBgtx, fluorescent-tagged Bgtx; IICR, inositol-induced calcium release; $I P_{3}$, inositol triphosphate; $I P_{3} R$, IP $P_{3}$ receptor; $n A C h R$, nicotinic acetylcholine receptor; PAM, positive allosteric modulator; PC12, pheochromocytoma cell line 12; PDI, protein disulfide isomerase; PH, Pleckstrin homology domain; PLC, phospholipase C; Ry, ryanodine; RyR, Ry receptor; Xest. C, Xestospongin C. 
receptors bind and activate the heterotrimeric $\mathrm{G}$ protein $\mathrm{G} \alpha \mathrm{q}$, leading to phospholipase C (PLC)-linked IICR and activation of downstream second messenger pathways such as RhoA (Nordman and Kabbani, 2014; King et al., 2015). Studies from our laboratory and others suggest that $\alpha 7 \mathrm{nAChRs}$ operate through both ionotropic and metabotropic signaling modes, although this distinction remains unclear (Nordman and Kabbani, 2012; Zhong et al., 2013; Kabbani and Nichols, 2018). In this study, we examined the effects of PNU120596 on calcium signaling by the $\alpha 7 \mathrm{nAChR}$ in pheochromocytoma line 12 (PC12) cells, building on previous studies that indicate that agonists of the $\alpha 7 \mathrm{nAChR}$ mediate calcium signaling through coupled store release. The current findings confirm that this PAM augments calcium signaling by the $\alpha 7$ receptor through augmented coupling between the channel receptor and the endoplasmic reticulum (ER). A new stochastic computational model depicting spatiotemporal $\alpha 7 \mathrm{nAChR}$ calcium dynamics in the cell corroborates the findings.

\section{Materials and Methods}

Cell Culture and DNA Transfection. PC12 (American Type Culture Collection, Manassas, VA; CRL1721TM) cells were grown on a poly-D-lysine $(100 \mu \mathrm{g} / \mathrm{ml})$ matrix and differentiated by the addition of 2.5-s mouse nerve growth factor ( $200 \mathrm{ng} / \mathrm{ml}$; Millipore, Billerica, MA) in PC12 media RPMI media (American Type Culture Collection), $10 \%$ horse serum, $5 \%$ fetal bovine serum, and $1 \%$ penicillin streptomycin (Thermo Fisher, Waltham, MA), as previously described in Nordman and Kabbani (2012). Cells were transfected with plasmids using Lipofectamine 2000, according to the manufacturer's protocol (Thermo Fisher). Cells were transfected and differentiated for 72 hours before each experiment. Plasmids used in this study have been previously characterized: GCaMP5G (Akerboom et al., 2012), human $\alpha 7 \mathrm{nAChR}$ (Saragoza et al., 2003), human $\alpha 7_{345-348 \mathrm{~A}}$ (King et al., 2015), rat $\alpha 7_{\mathrm{D} 44 \mathrm{~A}}$ (Colón- Sáez and Yakel 2014), and PH-mCherry (Chisari et al., 2009; Nordman and Kabbani, 2014). Plasmid DNA was purified using a maxi prep kit (Xymo Research, Irvine, CA).

Drug Treatment. Drugs were dissolved into Hanks' balanced salt solution or dimethylsulfoxide vehicle solution. Drug concentrations were determined based on established pharmacological data and previously published reports: the $\alpha 7$-specific agonist choline (1 and $3 \mathrm{mM}$; Acros Organics, Geel, Belgium); the $\alpha 7$-specific type II PAM PNU120596 (Zhang et al., 2015) (1 $\mu \mathrm{M})$ (Tocris, Bristol, United Kingdom); nonmembrane permeable calcium chelator 1,2-bis(2aminophenoxy)ethane- $N, N, N^{\prime}, N^{\prime}$-tetraacetic acid ( $\mathrm{Gu}$ and Yakel, 2011) (10 mM) (Thermo Fisher); the $\alpha 7$-specific antagonist $\alpha$-bungarotoxin (Bgtx) (Chan and Quik 1993) (50 nM); the ryanodine inhibitor ryanodine (Zhong et al., 2013) (30 $\mu \mathrm{M})$ (Santa Cruz Biotechnology, Santa Cruz, CA); the inositol triphosphate $\left(\mathrm{IP}_{3}\right)$-specific inhibitor Xestospongin C (Xest. C) (Nordman and Kabbani, 2014) (1 $\mu \mathrm{M}$ ) (Tocris); the broad $\alpha 7$ agonists nicotine and acetylcholine (Jones and Yakel, 1997) (50 $\mu \mathrm{M})$; and Rho A inhibitor I (King and Kabbani, 2016) (4 $\mu \mathrm{g} / \mathrm{ml})$ (Cytoskeleton, Denver, CO).

Immunocytochemistry and Fluorescence Detection. Cells were fixed in $1 \times$ of the following: $80 \mathrm{mM}$ 1,4-piperazinediethanesulfonic acid, $5 \mathrm{mM}$ EGTA, and $1 \mathrm{mM} \mathrm{MgCl} 2, \mathrm{pH} 6.8$, containing $0.3 \%$ glutaraldehyde, and then permeabilized (following cell surface labeling) with $0.05 \%$ Triton X-100 (He et al., 2005). Two milligrams per milliliter sodium borohydride was used for glutaraldehyde quenching prior to immunoblocking with $10 \%$ goat serum (Life Technologies, Carlsbad, CA). An anti-protein disulfide isomerase (PDI) antibody was used for ER labeling (Enzo Scientific, Ann Arbor, MI), and carbocyanine 2 (Jackson ImmunoResearch, West Grove, PA) was used as a secondary antibody. Cell surface detection of $\alpha 7 \mathrm{nAChRs}$ was performed, as previously described (Nordman and Kabbani, 2012), in nonpermeabilized cells using $50 \mathrm{nM}$ Alexa Fluor 488 conjugated to Bgtx. Cells were visualized using an inverted Zeiss LSM800 confocal microscope, and images were captured with Zen software (Carl Zeiss AG, Oberkochen, Germany) and processed in ImageJ (National Institutes of Health, Bethesda, MD). Signals were obtained using 405- and 488-nm excitation lasers, respectively. Heat maps showing colocalization were generated using Photoshop CS5 (Adobe Systems, San Jose, CA). Imaging experiments were repeated in three separate trials $(n=20)$.

Calcium Imaging. PC12 cells were transfected with the calcium sensor protein GCaMP5G and differentiated with nerve growth factor, as previously described (Nordman and Kabbani, 2012). Imaging was done in clear Hanks' balanced salt solution media (Thermo Fisher) equilibrated to room temperature, and drugs were added using a gravity-fed profusion system. Calcium transients were measured above the threshold of 3 S.D. from the baseline average that was obtained from the first 20 frames of each recording. Transient duration was measured from the first to last response value above the threshold. Changes in intracellular calcium were measured using an inverted Zeiss LSM800 confocal microscope at an acquisition rate of 1 frame per $256 \mathrm{~ms}$ for $45 \mathrm{~s}$ at $2 \times 2$ binning. All measures were done at room temperature. Phototoxicity and photobleaching were minimized using low-wavelength and neutral density light filters. Drugs were applied after a 50-frame baseline recording. Changes in the intracellular calcium signal were calculated from changes in the fluorescence of GCaMP5G $\left(\Delta \mathrm{F} / \mathrm{F}_{\theta}\right)$ using ImageJ (National Institutes of Health), and all measures are the result of examining regions of interest in the growth cone. When drug preincubations are indicated, the preincubation step occurred for 30 minutes prior to the imaging experiment. Experiments were repeated in three independent trials $(n=20)$.

PLC Assay. PLC activation was detected by imaging the translocation of the Pleckstrin homology (PH) domain of PLC- $\delta$ tagged with mCherry (PH-mCherry), as previously reported (Chisari et al., 2009; Nordman and Kabbani, 2014). PH-mCherry fluorescence was measured at the excitation wavelength $\lambda=555 \mathrm{~nm}$, and the dynamics of translocation were visualized at an acquisition rate of 1 frame per $10 \mathrm{~s}$ for 1 minute with $2 \times 2$ binning. Drugs were applied $20 \mathrm{~s}$ after a oneframe (10-s) baseline recording within the same region of interest. $\mathrm{PLC}$ activation can be inferred from the translocation of PH-mCherry, as shown (Chisari et al., 2009), using the equation $(\mathrm{Fm}-\mathrm{Fc}) /(\mathrm{Fm}+$ $\mathrm{Fc}$ ), where $\mathrm{Fm}$ and $\mathrm{Fc}$ refer to fluorescence at the plasma membrane and in the cytosol, respectively. Fluorescence values were normalized for surface area (square micrometer) measured with ImageJ (National Institutes of Health). The PLC assay was performed in three separate experiments $(n=8)$.

Computational Model Generation and Analysis. A new model that integrates the stochastic Monte Carlo models for ion channels is the $\mathrm{IP}_{3}$ receptor $\left(\mathrm{IP}_{3} \mathrm{R}\right)$ model of Ullah and Ullah, the RyR model developed by Williams et al. (2011), with an improved model for the $\alpha 7$ channel based upon the published model of Anderson et al., 2016; and Corradi and Bouzat, 2016 (McCormack et al., 2010; Williams et al., 2011; Andersen et al., 2016; Corradi and Bouzat, 2016; Ullah and Ullah, 2016). These models were chosen because they are well constrained by experimental data. For computational simplicity, a one-dimensional simulation was performed. Detailed equations and parameters for the model are presented in Supplemental Material. Supplemental Tables 1 and 2 detail symbols used in the Supplemental Material equations.

Statistical Analysis. Data are averaged as mean \pm S.D. and are representative of independent experiments in each assay. Statistical analysis was obtained via a one-way analysis of variance (ANOVA), or, where applicable, a paired two-tailed Student's $t$ test, to determine significance between mean values. All statistical values were obtained using SPSS 24 (IBM, Armonk, NY). A Fischer least significant difference post hoc test was used for individual comparisons. A minimum value $P<0.05$ was considered significant. 


\section{Results}

Allosteric Modulation of the $\alpha 7$ nAChR by PNU120596 Increases Intracellular Calcium. The $\alpha 7 \mathrm{nAChR}$ maintains the greatest calcium permeability among the $\mathrm{nAChR}$ types, contributing to not only cellular calcium level activity but also various forms of calcium signaling in cells (Le Novère et al., 2002). We have shown an important role for $\alpha 7$ activation in neurite growth through calcium signaling in the growth cone of differentiating PC12 cells (Nordman and Kabbani, 2014). To examine the effects of the PNU120596 on $\alpha 7$-mediated calcium activity, we measured calcium changes in the growth cone using the genetically encoded calcium sensor protein GCaMP5G under conditions of $\alpha 7$ activation with the specific agonist choline or $\alpha 7$ activation by choline in the presence of PNU120596. In all of our experiments, PNU120596 was applied at the established effective concentration of $1 \mu \mathrm{M}$ (Zhong et al., 2013). Because the $\mathrm{EC}_{50}$ for choline at the $\alpha 7$ receptor site is $1.6 \mathrm{mM}$ (Alkondon et al., 1997), we tested the effects of $3 \mathrm{mM}$ choline on calcium transients throughout the study. Indeed, choline application was associated with a dose-dependent increase in the average peak of the calcium transient signal within PC12 cells ( $t$ test, $F=5.440, P=0.012$ ) $\left(\Delta \mathrm{F} / \mathrm{F}_{\theta}\right.$ for $1 \mathrm{mM}$ choline $=288.11 \% \pm 27.01 \% ; \Delta \mathrm{F} / \mathrm{F}_{\theta}$ for $3 \mathrm{mM}=$ $507.57 \% \pm 59.51 \%$ ) (Fig. 1A). This effect of choline on calcium transients was reduced by $91.23 \%$ (average change) by the $\alpha 7$-specific antagonist Bgtx (50 nM), confirming that pharmacological activation of the $\alpha 7$ receptor produces a robust cellular calcium transient (Nordman and Kabbani, 2014).

We determined the effect of allosteric regulation at the $\alpha 7$ receptor on the cellular calcium transient by coapplying PNU120596 and choline. As shown in Fig. 1B, PNU120596 coapplication increased the calcium transient by $958.18 \%$ compared with choline alone $\left(\Delta \mathrm{F} / \mathrm{F}_{\theta}=4858.25 \% \pm 468.66 \%\right)$ ( $t$ test, $F=88.878, P<0.001)$. In addition, PNU120596 coapplication was associated with prolonging the cholinedriven calcium signal by $1.45 \mathrm{~s}$, which represents a twofold increase in duration (Fig. 1). The effect of PNU120596 on the choline-mediated calcium transient was reduced by $-86.35 \%$ in the presence of $\operatorname{Bgtx}(50 \mathrm{nM})\left(\Delta \mathrm{F} / \mathrm{F}_{\theta}=662.99 \% \pm 62.04 \%\right)$ or the nonmembrane permeable calcium chelator 1,2-bis(2aminophenoxy)ethane- $N, N, N^{\prime}, N^{\prime}$-tetraacetic acid $(10 \mathrm{mM})$ $\left(\Delta \mathrm{F} / \mathrm{F}_{\theta}=311.82 \% \pm 37.17 \%\right)$ (Fig. 1B) (ANOVA: $F(2,92)=$ 41.881, $P<0.001$; post hoc $P<0.001$ for both groups compared with control). These results indicate that allosteric modulation of the $\alpha 7$ receptor with PNU120596 strongly augments the intracellular calcium transient response through extracellular calcium influx.

These findings were corroborated by experiments aimed at examining the effects of PNU120596 on $\alpha 7$ receptor activation by other agonists. Average calcium transient peak values $\left(\Delta \mathrm{F} / \mathrm{F}_{\theta}\right)$ for these studies are presented in Table 1. As shown in Fig. 2A, application of the broad nAChR agonist nicotine $(50 \mu \mathrm{M})$ enhanced intracellular calcium levels $\left(\Delta \mathrm{F} / \mathrm{F}_{\theta}=\right.$ $705.53 \% \pm 89.91 \%)$ above baseline, an effect that was diminished by Bgtx. Coapplication of PNU120596 increased the nicotine-associated calcium transient by $324.14 \%$, and this too was diminished by Bgtx treatment (ANOVA: $F(3,57)=14.190$, $P<0.00$, all post hoc comparison of nicotine + PNU120596 $P<0.001$ ). Treatment with acetylcholine (ACh; $50 \mu \mathrm{M})$ was also associated with a rise in intracellular calcium $\left(\Delta \mathrm{F} / \mathrm{F}_{\theta}=\right.$ $520.61 \% \pm 86.85 \%$ ) above baseline (Fig. 2B). ACh-mediated calcium transients were also dramatically augmented by PNU120596 coapplication, which raised them by $327.16 \%$ when compared with ACh treatment alone (ANOVA: $F(2,44)=$ $6.119, P=0.005$, post hoc comparison of ACh + PNU120596 to ACh alone, $P=0.001$ ). Application of Bgtx reduced the ability of PNU120596 to increase calcium transient generation by ACh (Fig. 2B), confirming the essential role of the $\alpha 7 \mathrm{nAChR}$ in calcium signaling.
A
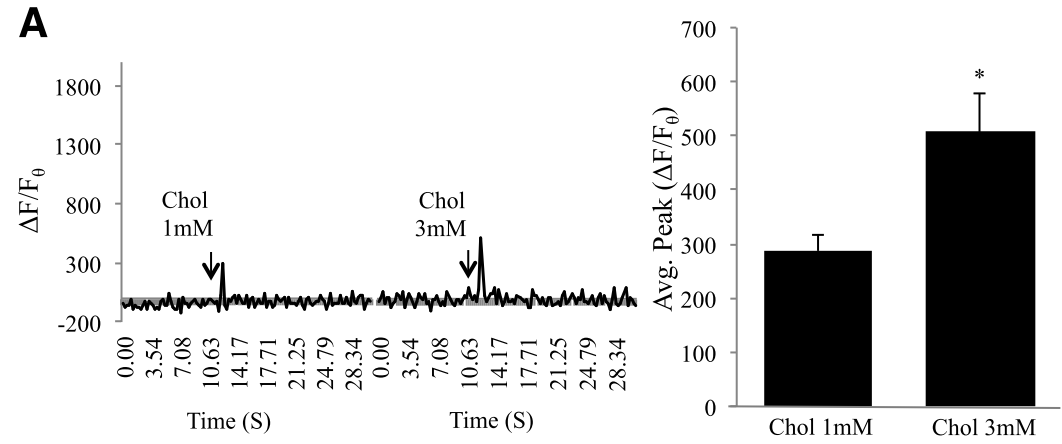

B

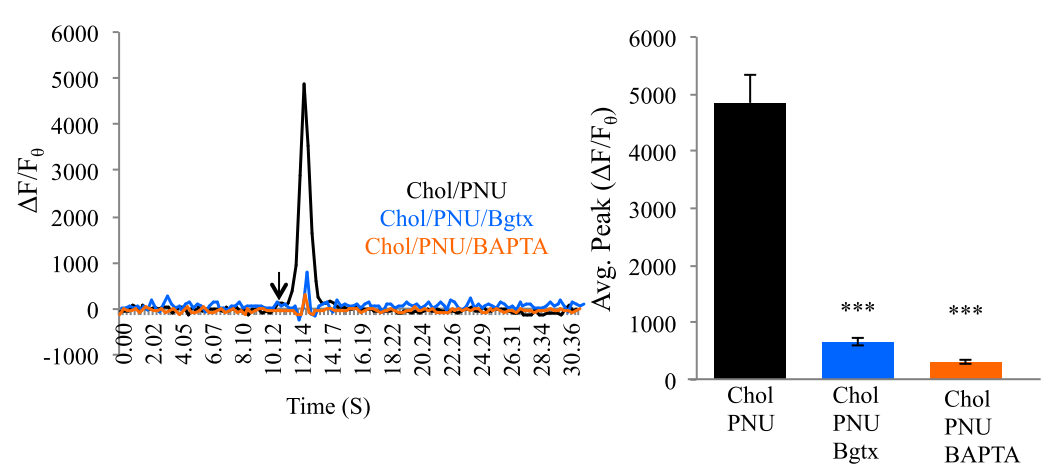

Fig. 1. PNU120596 augments choline-associated calcium transients. (A) Traces: calcium transient responses to application of the $\alpha 7$-specific agonist choline at 1 and $3 \mathrm{mM}$ concentrations. The arrow points to the time of drug application. Histogram: average calcium transient peak. (B) Traces: $3 \mathrm{mM}$ choline with $1 \mu \mathrm{M}$ PNU120596, pretreated with $50 \mathrm{nM}$ Bgtx, in the presence of the nonmembrane permeant calcium chelator 1,2-bis(2-aminophenoxy)ethane- $N, N, N^{\prime}, N^{\prime}$-tetraacetic acid $(10 \mathrm{mM}) .{ }^{*} P<0.05 ; * * * P<0.001$. Error bars represent S.D.; $n=22$ cells. 
TABLE 1

Average peak calcium transient measures following the application of nicotine (Nic, $50 \mu \mathrm{M})$, ACh $(50 \mu \mathrm{M})$, or $\alpha$-Bgtx (Bgtx, $50 \mathrm{nM})$ PNU120596 $(1 \mu \mathrm{M})$ was coapplied.

\begin{tabular}{lc}
\hline \multicolumn{1}{c}{ Drug } & $\Delta \mathrm{F} / \mathrm{F}_{\theta}$ \\
\hline Nic & $705.52 \% \pm 89.91 \%$ \\
Nic + Bgtx & $462.35 \% \pm 83.15 \%$ \\
Nic + PNU120596 & $2286.88 \% \pm 429.91 \%$ \\
Nic + PNU120596 + Bgtx & $437.01 \% \pm 76.68 \%$ \\
ACh & $520.61 \% \pm 85.85 \%$ \\
ACh + PNU120596 & $1702.21 \% \pm 302.48 \%$ \\
ACh + PNU120596 + Bgtx & $888.96 \% \pm 392.74 \%$ \\
\hline
\end{tabular}

PNU120596 Augments $\alpha 7$ nAChR Calcium Transients through Intracellular Store Release. Upon ligand activation, the $\alpha 7$ channel conducts sodium and calcium into the cell, with the latter contributing to calcium-induced calcium release from nearby ER (Zhong et al., 2013; Nordman and Kabbani, 2014; King et al., 2015). In various types of cells, $\alpha 7$ nAChRs are targeted close to the ER and thus positioned to regulate calcium store activity (Shen and Yakel, 2009). We confirmed colocalization of the $\alpha 7 \mathrm{nAChR}$ and the ER in PC12 cells using a dual labeling method in which the fluorescenttagged Bgtx (fBgtx) is used in conjunction with the ER marker protein PDI, respectively. In this assay, we detected $\alpha 7 \mathrm{nAChRs}$ at the cell surface by labeling prior to Triton permeabilization of the membrane. Noticeable coexpression of the two signals was seen throughout the cell; however, distinct subcellular colocalization was also observed. Specifically, strong overlap in the $\alpha 7 / \mathrm{ER}$ signal was seen within the soma and the growth cone (Fig. 3A). The strongest colocalization between the $\alpha 7 \mathrm{nAChR}$ and the ER was in the growth cone, consistent with earlier studies on functional coupling between the receptor and calcium stores during neurite growth (Nordman and Kabbani, 2014).

We assessed the ability of coapplication of PNU120596 and choline $3 \mathrm{mM}$ to modulate intracellular calcium levels in the presence of pharmacological agents that block calcium release from the ER. As shown in Fig. 3B and Table 2, pretreatment of cells with $30 \mu \mathrm{M}$ ryanodine ( $\mathrm{Ry}$ ) to block the Ry receptor (RyR) was associated with a $71.21 \%$ decrease in the calcium transient generated by the application of PNU120596 and choline. Inhibition of the $\mathrm{IP}_{3}$ receptor by pretreatment with $1 \mu \mathrm{M}$ Xest. $\mathrm{C}$ was associated with a $67.40 \%$ loss in the calcium transient generated by PNU120596 and choline coapplication. Coapplication of Ry and Xest C. also significantly decreased the calcium transient $(-73.67 \%)$. This is confirmed by ANOVA, showing that blocking the RyR, the $\mathrm{IP}_{3} \mathrm{R}$, or both the RyR and $\mathrm{IP}_{3} \mathrm{R}$ leads to a significant loss in calcium signal generation by PNU120596 and choline coapplication (Fig. 3C) [ANOVA: $F(3,135)=23.980, P<0.001$; post hoc: $P<0.001$ for all pretreatment groups].

A relative comparison of the effect of $\mathrm{IP}_{3} \mathrm{R}$ blockade by Xest. $\mathrm{C}$ and RyR blockade by Ry between choline and choline with PNU120596 indicates that modulation alters $\alpha 7$ coupling to the ER. In particular, in the presence of PNU120596, choline treatment drives a calcium transient with greater dependence on the RyR, as evidenced by the ability of Ry to inhibit calcium signals to a greater extent in cotreated cells (Fig. 3D). Interestingly, PNU120596 coapplication appears to also increase $\mathrm{IP}_{3} \mathrm{R}$-mediated IICR in comparison with choline alone. The experiments suggest a nonlinear relationship between RyR- and $\mathrm{IP}_{3} \mathrm{R}$-mediated calcium release in the presence of PNU120596 consistent with known interactions between RyR and $\mathrm{IP}_{3} \mathrm{R}$ pathways in cells (Verkhratsky, 2002). These findings support evidence on the ability of PNU120596 to prolong the open $\alpha 7$ channel state leading to enhanced calcium influx (Andersen et al., 2016).

Calcium Influx through the $\alpha 7 \mathrm{nAChR}$ Is Necessary for PNU120596-Mediated Calcium Signaling. Ligand activation of the $\alpha 7 \mathrm{nAChR}$ enables channel transition to an open state that conducts calcium ions across the plasma membrane; however, this state is short-lived because

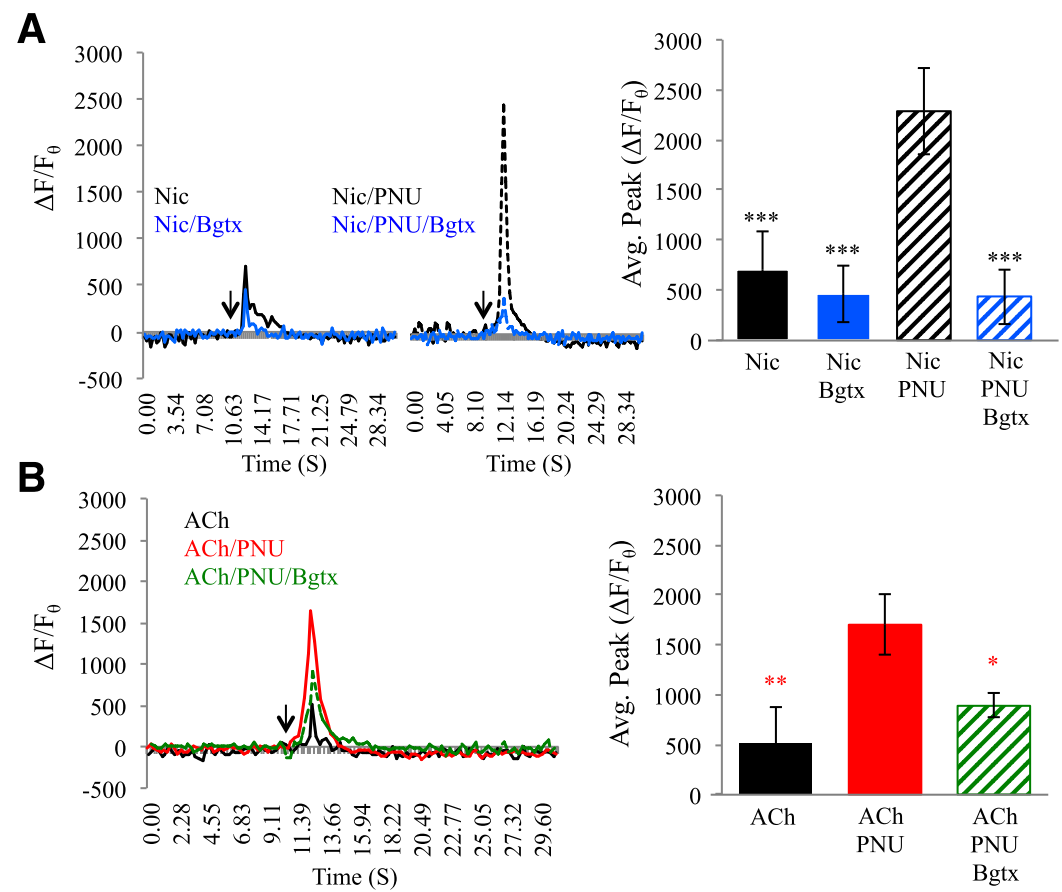

Fig. 2. PNU120596 enhances calcium transients by the $\alpha 7$ nAChR when activated by nicotine or ACh. (A) Traces: left, calcium transient responses to application of the $\alpha 7$ agonist nicotine (50 $\mu \mathrm{M}$; black) or nicotine and Bgtx ( $50 \mathrm{nM}$; light blue). Right, coapplication of nicotine and PNU120596 $(1 \mu \mathrm{M})$ or nicotine, Bgtx, and PNU120596. Histogram: average calcium transient peak. (B) Traces: left, calcium transient responses to application of $\mathrm{ACh}(50 \mu \mathrm{M}$; black) or ACh and PNU120596 ( $1 \mu \mathrm{M}$; red), or ACh, PNU120596, and Bgtx (50 nM; green). $* P<0.05 ; * * P<0.01$; $* * * P<0.001$ (asterisk color represents significant comparison with individual group); error bars represent S.D.; $n=22$ cells 
A
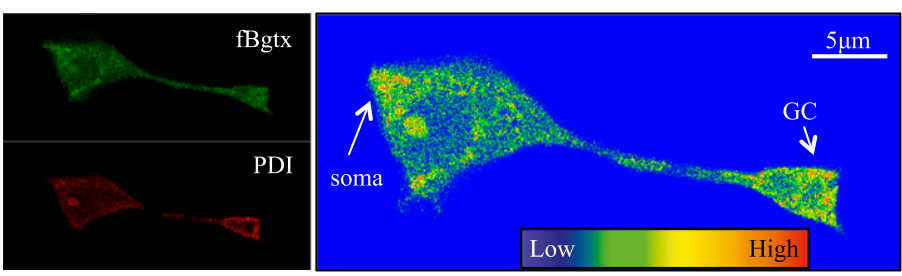

B
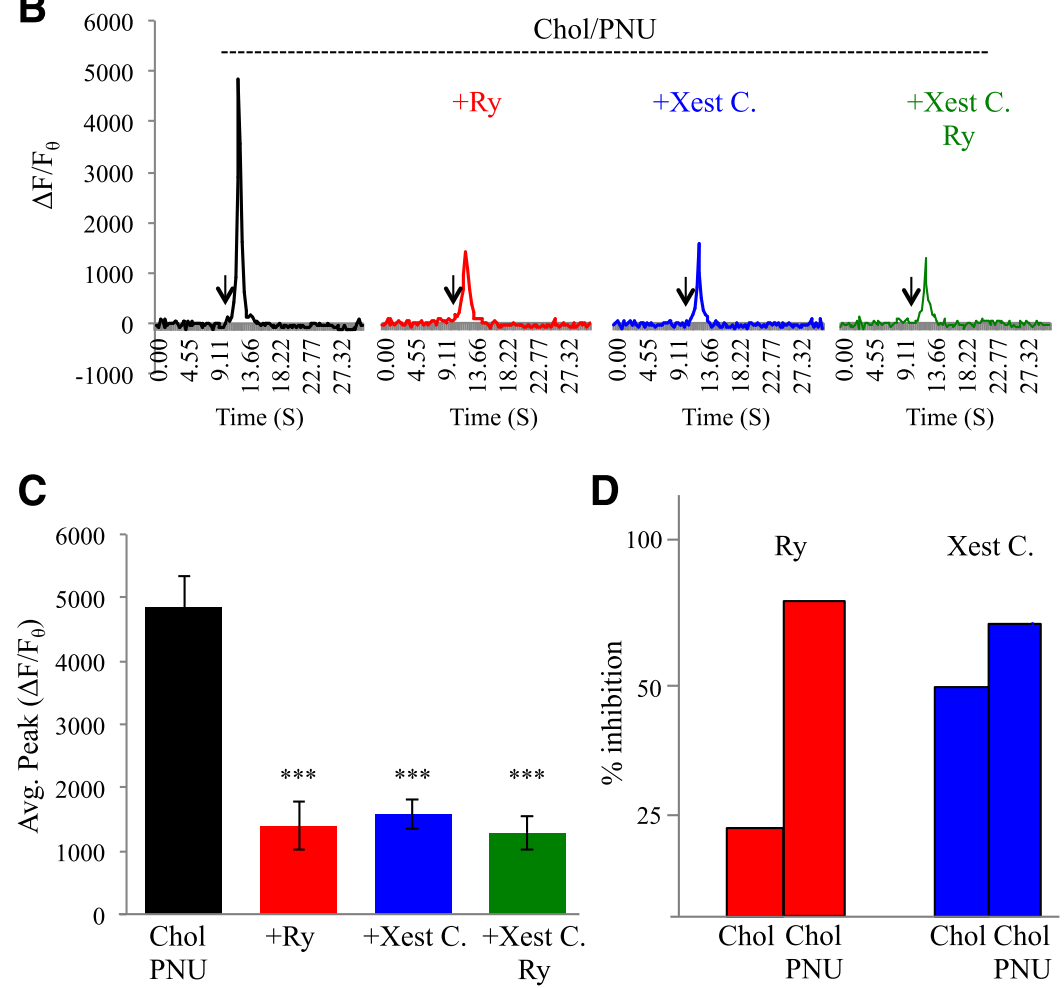

Fig. 3. Calcium signaling through the ER is enhanced by PNU120596. (A) Fluorescent detection of cell surface $\alpha 7$ nAChRs labeled with fBgtx and intracellular labeling of the ER using PDI. Heat map colocalization of the two signals shows strong overlap in the soma and growth cone (arrow). (B) Comparison of transient measures following coapplication of PNU120596 $(1 \mu \mathrm{M})$ and choline $(3 \mathrm{mM})$ in cells preincubated with Ry ( $30 \mu \mathrm{M}$; red), Xest. C ( $1 \mu \mathrm{M}$; blue), or both (green). (C) Average peak calcium transient for each group. (D) Percent inhibition of the average peak calcium transient response in cells treated with choline $(3 \mathrm{mM})$, or $3 \mathrm{mM}$ choline and PNU20596, when inhibitied by Ry or Xest. $\mathrm{C}(1 \mu \mathrm{M})$. ${ }^{* * *} P<0.001$; error bars represent S.D.; $n=$ 22 cells. the receptor quickly transitions into a desensitized state (Andersen et al., 2016; Corradi and Bouzat, 2016). PNU120596 is a prototypical type II PAM, which increases the open time of the $\alpha 7 \mathrm{nAChR}$ channel, promoting greater calcium conductance across the plasma membrane (Williams et al., 2012).

We tested the contribution of calcium entry through the $\alpha 7$ channel in PNU120596-associated calcium transient responses by utilizing the $\alpha 7_{\mathrm{D} 44 \mathrm{~A}}$ mutant, which has been shown to be impaired in permeability to calcium (Colón-Sáez and Yakel, 2014). The $\alpha 7_{\mathrm{D} 44 \mathrm{~A}}$ subunit expresses in PC12 cells and can operate as a dominant negative for calcium entry through the $\alpha 7$ channel (Nordman and Kabbani, 2014; King and Kabbani, 2016). Cell surface detection with fBgtx confirms $\alpha 7_{\mathrm{D} 44 \mathrm{~A}}$ expression at the cell surface and colocalization with the ER (Fig. 4A). Analysis of the $\alpha 7 \mathrm{nAChR}$ overexpression in $\left(\alpha 7^{+}\right)$cells revealed no statistical significance in the peak calcium transient when compared with the endogenous $\alpha 7$ nAChR baseline condition ( $\alpha 7)$ (Fig. 4B). Calcium-imaging experiments, however, showed a significant difference in the duration of the calcium transient between $\alpha 7$ and $\alpha 7^{+}$cells when cells were cotreated with PNU120596 and $3 \mathrm{mM}$ choline consistent with previous findings (King et al., 2015).

In previous studies, we have shown that $\alpha 7_{\mathrm{D} 44 \mathrm{~A}}$ expression is associated with a reduction in the ability of choline to enhanced intracellular calcium in PC12 cells (Nordman and Kabbani, 2014). Calcium-imaging experiments in this study indicate that transfection with $\alpha 7_{\mathrm{D} 44 \mathrm{~A}}$ is associated with a $45.37 \%$ decrease from $\alpha 7$ control and a $41.14 \%$ decrease from $\alpha 7^{+}$control cells when PNU120596 and $3 \mathrm{mM}$ choline are

TABLE 2

Average peak calcium transient measures following the coapplication of $3 \mathrm{mM}$ choline and $1 \mu \mathrm{M}$ PNU120596 in cells transfected with variants of the $\alpha 7$ receptor Cells were pretreated with Ry $(30 \mu \mathrm{M})$ or Xest. C $(1 \mu \mathrm{M})$.

\begin{tabular}{lccc}
\hline \multicolumn{1}{c}{ Receptor } & Vehicle $\left(\Delta \mathrm{F} / \mathrm{F}_{\theta}\right)$ & $\mathrm{Ry}\left(\Delta \mathrm{F} / \mathrm{F}_{\theta}\right)$ & Xest. C $\left(\Delta \mathrm{F} / \mathrm{F}_{\theta}\right)$ \\
\hline$\alpha 7_{\text {endogenous }}$ & $4858.25 \% \pm 468.65 \%$ & $1398.76 \% \pm 382.33 \%$ & $1583.34 \% \pm 240.76 \%$ \\
$\alpha 7_{\mathrm{D} 44 \mathrm{~A}}$ & $2654.13 \% \pm 498.24 \%$ & $1115.99 \% \pm 234.19 \%$ & $1696.25 \% \pm 259.46 \%$ \\
$\alpha 7_{345-348 \mathrm{~A}}$ & $3322.11 \% \pm 474.83 \%$ & $1965.54 \% \pm 282.33 \%$ & $2647.60 \% \pm 432.65 \%$ \\
\hline
\end{tabular}


A
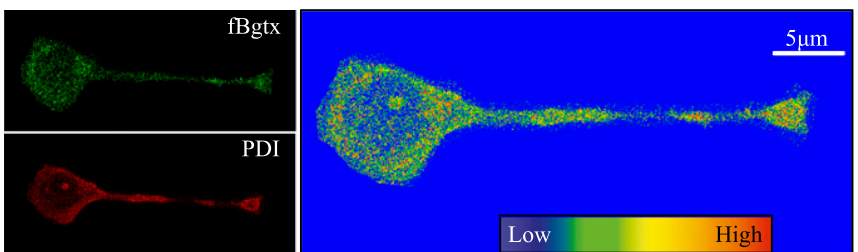

B
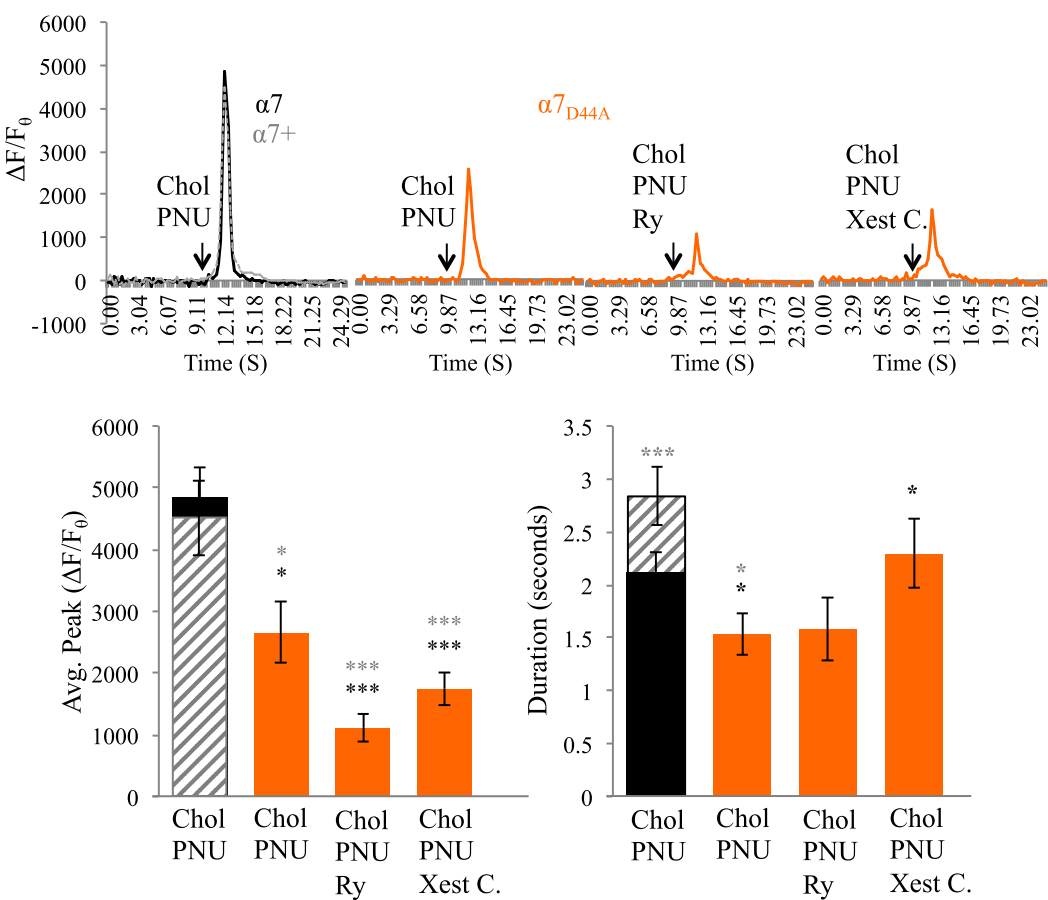

Fig. 4. Decrease in calcium conductance following $\alpha 7_{\mathrm{D} 44 \mathrm{~A}}$ expression attenuates calcium signaling by PNU120596. (A) Fluorescent detection of cell surface $\alpha 7 \mathrm{nAChRs}$ in $\alpha 7_{\mathrm{D}_{44} \mathrm{~A}^{-}}$ transfected cells labeled with fBgtx and intracellular labeling of the ER using PDI. Heat map colocalization of the two signals shows strong overlap in the soma and growth cone. (B) Traces: a comparison of transient measures following coapplication of PNU120596 (1 $\mu \mathrm{M})$ and choline $(3 \mathrm{mM})$ in $\alpha 7_{\mathrm{D} 44 \mathrm{~A}}$-transfected cells (orange) preincubated with $\mathrm{Ry}$ $(30 \mu \mathrm{M})$ or Xest. C $(1 \mu \mathrm{M})$. Control conditions: endogenous $\alpha 7$ expression (black solid); transfected with human $\alpha 7\left(\alpha 7^{+}\right)$ (gray broken line). Histogram: left, average calcium transient peak; right, average duration of the calcium transient $* P<0.05$; $* * * P<0.001$ (asterisk color represents significant comparison with individual group); error bars represent S.D.; $n=24$ cells. coapplied [ANOVA: $F(4,148)=13.439, P<0.001$; post hoc to endogenous $P=0.012$; post hoc to $\alpha 7^{+} P=0.024$ ) (Fig. 4B; Table 2). Pretreatment of $\alpha 7_{\mathrm{D} 44 \mathrm{~A}}$-transfected cells with either Ry or Xest C. led to a greater reduction in calcium signaling following choline/PNU120596 coapplication (post hoc $P<$ 0.001 when compared with both controls). A comparison of the effects of $\alpha 7_{\mathrm{D} 44 \mathrm{~A}}$ expression on the intracellular calcium transients following pretreatment reveals a greater loss in calcium transient responses in the presence of $\mathrm{Ry}$ when compared with the presence of Xest C. (Fig. 4B). Transfection with $\alpha 7_{\mathrm{D} 44 \mathrm{~A}}$ also significantly decreased the duration of the calcium transient relative to controls [ANOVA: $F(4,148)=$ $2.453, P=0.048$; post hoc to endogenous $P=0.012$; post hoc to $\left.\alpha 7^{+} P=0.020\right]$.

Enhanced Calcium Signaling Is Lost When the $\alpha 7$ nAChR Does Not Bind G Proteins. $\alpha 7 \mathrm{nAChRs}$ operate through ionotropic and metabotropic modes and can regulate immediate as well as long-term signal transduction in cells (King et al., 2015; King and Kabbani, 2016). Recent studies suggest a role for allosteric modulators in altering metabotropic signaling by nAChRs (Andersen et al., 2016; Corradi and Bouzat, 2016). We have shown that the $\alpha 7$ receptor can directly activate $\mathrm{G} \alpha \mathrm{q}$, leading to downstream signaling via PLC- and $\mathrm{IP}_{3}$-associated IICR in PC12 cells (King et al., 2015). We tested the ability of PNU120596 to modulate calcium through $\mathrm{G}$ proteins by transfecting cells with a dominantnegative $\alpha 7$ subunit harboring a mutation at the $\mathrm{G}$ protein- binding cluster located within the M3-M4 intracellular loop region $\left(\alpha 7_{345-348 \mathrm{~A}}\right)$ (King et al., 2015). As shown in Fig. 5A, expression of the $\alpha 7_{345-348 \mathrm{~A}}$ subunit does not interfere with cell surface localization nor the distribution of fBgtx labeling. In addition, colocalization of the fBgtx and the PDI signal appears similar in cells transfected with the $\alpha 7_{345-348 \mathrm{~A}}$ mutant as control cells [cells transfected with an empty vector or native (nontransfected) cells] (Fig. 5A and data not shown).

Coapplication of choline and PNU120596 was associated with a significant decrease in the calcium transient within $\alpha 7_{345-348 \mathrm{~A}^{-} \text {-expressing cells relative to } \alpha 7 \text { control cells }(31.62 \%)}$ as well as $\alpha 7^{+}$control cells $(26.33 \%$ ) (Fig. 5B; Table 2) [ANOVA: $F(4,191)=9.824, P<0.001$; post hoc $P=0.014$ to control; post hoc $P=0.025$ to $\alpha 7^{+}$-expressing cells]. Experiments indicate that expression of $\alpha 7_{345-348 \mathrm{~A}}$ is associated with a loss in the ability of PNU120596 to modulate cholineassociated calcium transients through disrupting coupling between the $\alpha 7 \mathrm{nAChR}$ and the ER. Pretreatment with Ry led to a significant decrease in calcium transients in $\alpha 7(-59.55 \%)$ and $\alpha 7^{+}(-56.42 \%)$ cells (post hoc $\left.P<0.001\right)$. In cells transfected with $\alpha 7_{345-348 \mathrm{~A}}$, pretreatment with Ry was also associated with a reduction $(-40.83 \%)$ in the ability of PNU120596 to modulate choline-evoked calcium release (post hoc $P=0.024$ compared with $\alpha 7_{345-348 \text { A PNU120596/choline }}$ none-pretreated cells). Pretreatment with Xest C. weakened the ability of PNU120596 to modulate the choline cal-

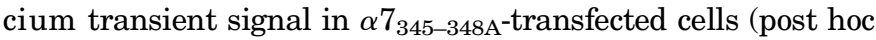


A
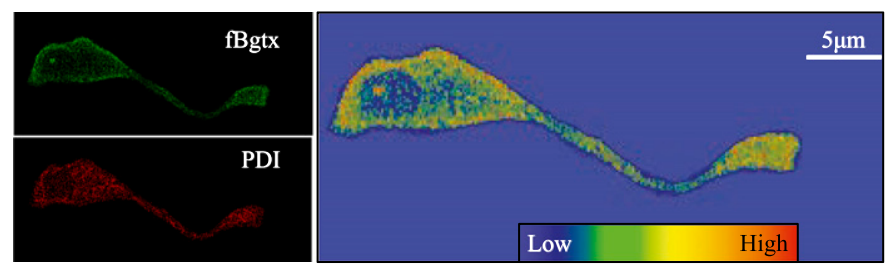

B

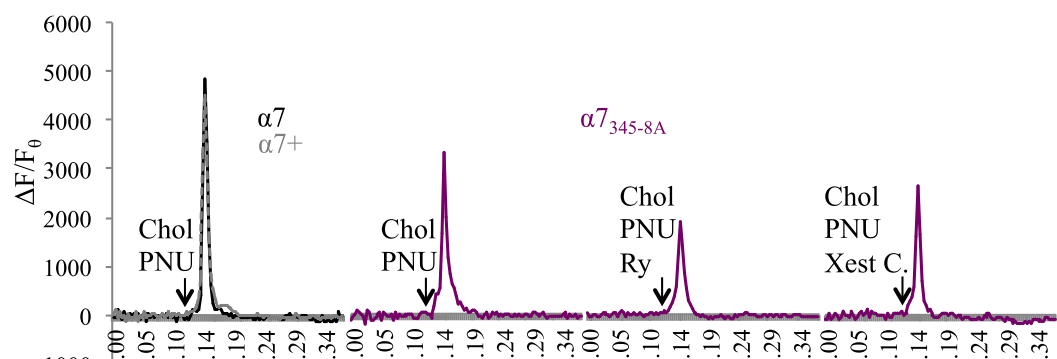

-1000 b


Fig. 5. Loss of $\mathrm{G}$ protein binding in $\alpha 7_{345-348 \mathrm{~A}}$-expressing cells reduces calcium signaling by PNU120596. (A) Fluorescent detection of cell surface $\alpha 7 \mathrm{nAChRs}$ in $\alpha 7_{345-348 \mathrm{~A}}$ labeled with fBgtx and intracellular labeling of the ER using PDI. Heat map colocalization of the two signals shows strong overlap in the soma and growth cone. (B) Traces: a comparison of transient measures following coapplication of PNU120596 (1 $\mu \mathrm{M})$ and choline $(3 \mathrm{mM})$ in $\alpha 7_{345-348 \mathrm{~A}^{-}}$ transfected cells (purple) preincubated with Ry $(30 \mu \mathrm{M})$ or Xest. C ( $1 \mu \mathrm{M})$. Control conditions: endogenous $\alpha 7$ expression (black solid); transfected with human $\alpha 7\left(\alpha 7^{+}\right)$(gray broken line). Histogram: left, average calcium transient peak; right, average duration of the calcium transient. $* * P<0.01$; *** $P<0.001$ (asterisk color represents significant comparison with individual group); error bars represent S.D.; $n=24$ cells.
$P<0.001$ to $\alpha 7$; post hoc $P=0.001$ to $\alpha 7^{+}$) (Fig. 5B; Table 2). Because a loss in $\mathrm{G}$ protein coupling within $\alpha 7_{345-348 \mathrm{~A}}$ attenuates the ability of the $\alpha 7$ receptor to activate $\mathrm{IP}_{3} \mathrm{R}$ (King et al., 2015), these findings support earlier experiments showing that PNU120596 modulation of the $\alpha 7 \mathrm{nAChR}$ augments RyRmediated CICR.

Positive Allosteric Modulation of the $\alpha 7 \mathrm{nAChR}$ Activates PLC Signaling. $\alpha 7 \mathrm{nAChR}$ activation leads to second messenger signaling PLC in hippocampal axons, growing neurites, and dorsal root ganglia neurons, leading to calcium signaling and release (Santos et al., 2013; Nordman and Kabbani, 2014; King et al., 2015). We tested the ability of PNU120596 to impact PLC signaling through $\alpha 7$ receptor activation in the growth cone. To do this, we used live cell imaging to track the translocation of the fluorescent protein sensor PLC $(\delta)$ tagged with mCherry (PH-mCherry) from the cell surface to the cytoplasm within the growth cone (Chisari et al., 2009; Nordman and Kabbani, 2014; King et al., 2015). At $3 \mathrm{mM}$, choline was associated with a translocation of the PH-mCherry probe from the membrane to the cytoplasm, where it largely localized to the cytoplasm at $50 \mathrm{~s}$ after drug application (Fig. 6). Coapplication of PNU120596 and choline enhanced the rate of $\mathrm{PH}-\mathrm{mCherry}$ translocation with maximal signal detection in the cytoplasm at $20 \mathrm{~s}$ after the start of treatment (Fig. 6). These results demonstrate that
PNU120596 augments $\alpha 7$ nAChR signaling through PLC, likely contributing to faster and greater $\mathrm{IP}_{3}$ production and IICR.
A

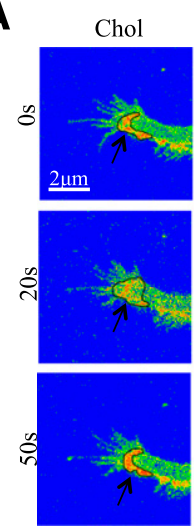

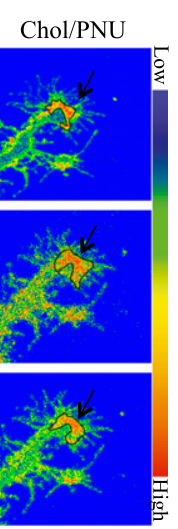

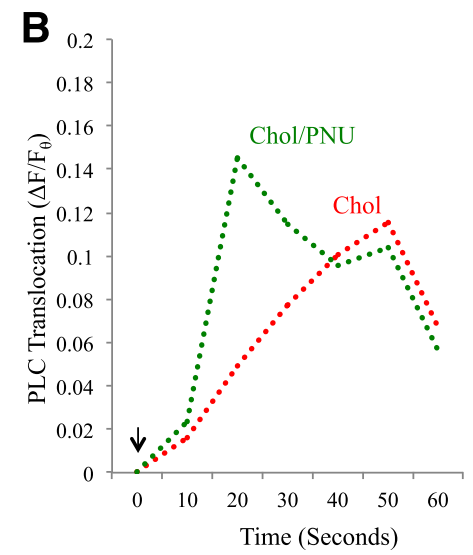

Fig. 6. PNU120596 augments PLC signaling. PLC activation was measured by translocation of the $\mathrm{PH}-\mathrm{mCh}$ Crry sensor from the cell surface to the cytosol. (A) A heat map of PH-mCherry imaging at the growth cone at 0 , 20 , and $50 \mathrm{~s}$ of treatment with choline $(3 \mathrm{mM})$ or choline and PNU120596 (1 $\mu \mathrm{M})$. Black line surrounding region of interest areas of strong signal measure. (B) Time course of PH-mCherry translocation in response to choline $(3 \mathrm{mM})$ or choline and PNU120596 $(1 \mu \mathrm{M})$. Arrow: time of drug application; $n=10$ cells. 
A Computational Model of Allosteric Mechanisms Underlying Calcium Signaling by the $\alpha 7$ Receptor. Experiments in this study, as well as those conducted previously, suggest dynamic interplay between $\alpha 7, \mathrm{IP}_{3}$, and Ry receptor proteins in the growth cone. We hypothesize that under normal full agonist activation of the $\alpha 7 \mathrm{nAChR}$, metabotropically generated $\mathrm{IP}_{3}$ is produced and diffuses to activate $\mathrm{Ca}^{2+}$ release from nearby $\mathrm{IP}_{3} \mathrm{Rs}_{\mathrm{s}}$ through a process dominated by IICR and G protein signaling (Nordman and Kabbani, 2014). The application of $\alpha 7$ open channel enhancers such as PNU120596, however, results in an increase in the open time of the channel, thus fostering a larger calcium influx in the cell. This process favors a shift to CICR through RyR opening in nearby ER. Given the varied kinetics of $\mathrm{IP}_{3} \mathrm{R}$ and RyR and the altered time course of $\alpha 7$ channel opening, the actions of a PAM may significantly impact local calcium dynamics. To test this, a spatiotemporal computational model of $\mathrm{Ca}^{2+}$ dynamics in the growth cone was developed. The model accurately simulates growth cone $\mathrm{Ca}^{2+}$ signal responses based on $\alpha 7$ channel kinetics and rate constants published in literature (Corradi and Bouzat, 2016). Simulation experiments indicate that PNU120596 modulation is associated with enhanced intracellular calcium relative to agonist application alone (Fig. 7, C-E). PNU120596 coapplication was in fact associated with a fourfold increase in the concentration of intracellular calcium similar to calcium measures in PC12 cells (Fig. 7D). The model also predicts that calcium concentration near the nAChR channel (local calcium concentrations) is much higher, however, and peaks at $\sim 25 \mu \mathrm{M}$ in free calcium concentration within the subcellular microdomain space between the $\mathrm{nAChR}$ and the ER membrane (Fig. 7E). Thus, $\alpha 7$ receptor placement is critical for ER-associated $\mathrm{Ca}^{2+}$ release, and ligand-activated calcium signals in the model are best matched to experimental findings when the $\mathrm{nAChR}$ and the ER are 10-15 $\mathrm{nm}$ apart. Computational simulations reveal that increases in local calcium concentrations following PNU120596 modulation are sufficient to activate the RyR, leading to CICR. Measures of calcium flux through the RyR show that a considerable level of calcium is released from the ER for longer time periods when PNU120596 is bound to the $\alpha 7$ channel (Fig. 7G). The $\alpha 7$-mediated IICR is also enhanced by PNU120596 in the model, and in cellular experiments, but in this work too IICR appears less impacted by the presence of the PAM than CICR (Fig. 7F).

\section{Discussion}

Although it has been proposed that many different states of the $\alpha 7 \mathrm{nAChR}$ may exist following ligand binding, it remains
A

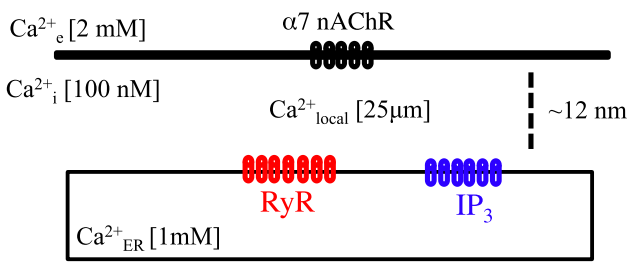

C

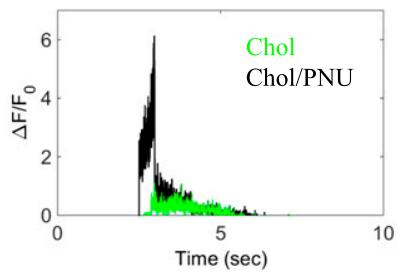

$\mathbf{F}$

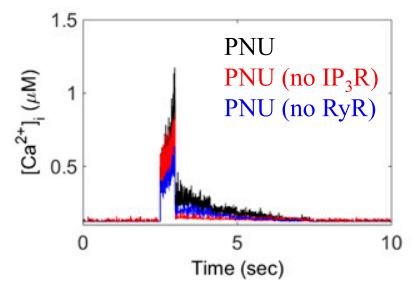

D

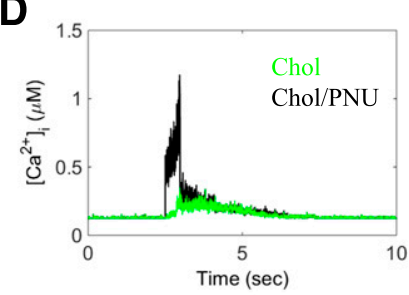

G

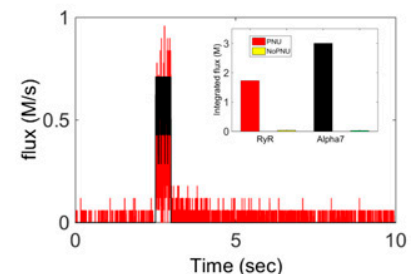

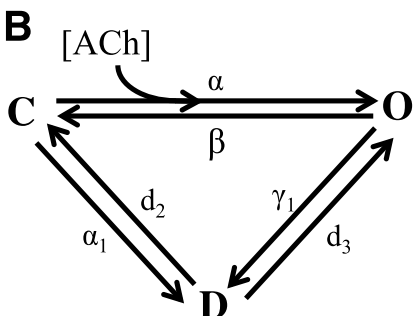

E



H

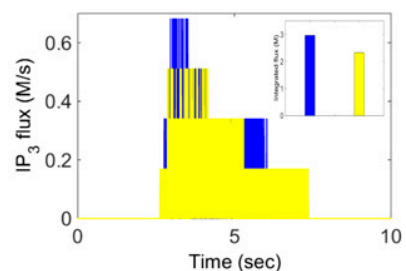

Fig. 7. Modeling mechanisms of ligand-induced calcium signaling. (A) Model schematic showing the spatial dynamics of the $\alpha 7$ channel, the RyR, and $\mathrm{IP}_{3} \mathrm{R}$. (B) Kinetic scheme for the $\alpha 7$ channel indicating closed (C), open (O), and desensitized (D) states. Transition rates between various states are indicated in Supplemental Material. (C) Simulated $\mathrm{Ca}^{2+}$ fluorescence is represented by the amount of $\mathrm{Ca}^{2+}$ bound to indicator dye $\left[\left(\left[\mathrm{Ca}{ }^{2+} \mathrm{F}\right]-\right.\right.$ $\left.\left[\mathrm{Ca}^{2+} \mathrm{F}\right]_{\text {baseline }} /\left[\mathrm{Ca}^{2+} \mathrm{F}\right]_{\text {baseline }}\right]$. The addition of PNU120596 increases the magnitude of the measured calcium transient over the ACh baseline (green) and ACh with PNU120596 (black). (D) The model allows visualization of the increase in the intracellular calcium concentration ([Ca $\left.\left.{ }^{2+}\right]_{\mathrm{i}}\right)$ with the addition of PNU120596. (E) The model predicts local calcium concentrations $\left(\left[\mathrm{Ca}^{2+}\right]_{\text {local }}\right)$ near the $\alpha 7$ receptor, which are elevated by PNU120596. (F) Simulation of $\left[\mathrm{Ca}^{2+}\right]_{\mathrm{i}}$ generated by PNU120596 and ACh (black) is reduced by blocking the RyR (blue) or blocking the $\mathrm{IP}_{3} \mathrm{R}$ (red). (G) Simulations of calcium flux through open $\alpha 7$ (black) and RyR (red) clusters in the presence of ACh and PNU120596. Inset: integrated $\alpha 7$ calcium flux in the presence of the agonist (black) is augmented by the addition of PNU120596 (red). (H) Simulations of $\mathrm{IP}_{3} \mathrm{R}$ calcium flux generated by ACh activation of the $\alpha 7 \mathrm{nACh}$ with (blue) or without (yellow) PNU120596. Inset: the integrated fluxes for the period of agonist stimulation (approximately 2.5-3.0 s). 
unclear how these states affect global signaling within cells (Le Novère et al., 2002; Bocquet et al., 2009; Bouzat et al., 2017). In this study, we demonstrate that activation of the $\alpha 7$ $\mathrm{nAChR}$ is tightly coupled to ER calcium store release and that this process is subject to regulation by allosteric-acting compounds such as PNU120596. Specifically, choline activation of the $\alpha 7 \mathrm{nAChR}$ either by itself, or in combination with PNU120596, leads to a significant rise in intracellular calcium through calcium store release. This process can be directly measured as robust calcium transient with a discreet peak in its amplitude and duration across various experimental conditions. Similar to choline treatment, the application of nicotine or the endogenous neurotransmitter ACh can mediate $\alpha 7 \mathrm{nAChR}$ calcium signaling that is altered by PNU120596 coapplication, suggesting that allosteric site occupancy impacts calcium signaling. Interestingly, calcium signaling was seen even in the presence of Bgtx when ACh or nicotine was applied, consistent with the finding of other types of cholinergic receptors in PC12 cells, which express several other nAChR subunits, including $\alpha 3, \alpha 5, \beta 2, \beta 3$, and $\beta 4$, and muscarinic receptors (Rogers et al., 1992).

Our experiments clearly show that the $\alpha 7$-driven calcium transient consists of a RyR-mediated CICR and an $\mathrm{IP}_{3} \mathrm{R}$ mediated IICR component operating in a synergistic manner to augment calcium release in response to $\alpha 7 \mathrm{nAChR}$ activation. Compounds such as PNU120596 thus appear to operate, at least in part, through an ability to enhance coupling between the $\alpha 7 \mathrm{nAChR}$ and the ER when the receptor resides in close proximity to this organelle. We tested our hypothesis through pharmacological, genetic, and computational methods, building upon a well-established body of literature that demonstrates $\alpha 7$ specificity for calcium signaling (Zhong et al., 2013; Nordman and Kabbani, 2014; Cheng and Yakel, 2015; King et al., 2015). In one set of experiments, we explored the ability of PNU120596 to regulate calcium signaling in cells transfected with the $\alpha 7_{\mathrm{D} 44 \mathrm{~A}}$ subunit, which harbors a mutation at amino acid position 44 in the amino terminus extracellular receptor region, resulting in a $64 \%$ lowered channel conductance of calcium (Colón-Sáez and Yakel, 2014). From earlier work, we knew that expression of the $\alpha 7_{\mathrm{D} 44 \mathrm{~A}}$ mutant in the PC12 cell is possible and associated with aberrances in $\alpha 7$ signaling during neurite growth (King and Kabbani, 2016). Experiments in this study show that calcium entry through the $\alpha 7$ channel is critical for PNU120596 modulation of calcium release from the ER involving both CICR and IICR. In a second series of studies, we examined the capacity of PNU120596 to alter metabotropic G protein signaling by $\alpha 7$ receptors by transfecting the $\alpha 7_{345-348 \mathrm{~A}}$ subunit, which is impaired in G protein binding (King et al., 2015). Experiments using the $\alpha 7_{345-348 \mathrm{~A}}$ subunit confirm the involvement of G protein-coupled IICR in the mechanism of action of PAM modulation because the effects of PNU120596 on calcium signaling were also diminished in cells expressing this mutant. Based on the data, however, G protein-associated metabotropic signaling by the $\alpha 7$ receptor appears relatively less impacted by the modulatory actions of PNU120596 than CICR. Based on these findings, we propose that calcium influx through the open $\alpha 7$ channel leading to CICR is an essential component of PNU120596 actions on cellular calcium signaling and may be a mechanism for its efficacy in drug development (Fig. 8).



B

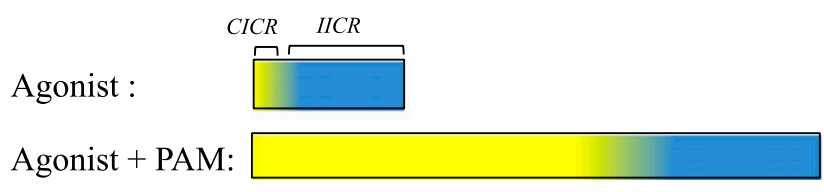

Fig. 8. $\alpha 7 \mathrm{nAChR}$ calcium signaling and its modulation. $\alpha 7 \mathrm{nAChRs}$ localize to calcium microdomains, which enable coupling between the receptor and the ER. (A) Allosteric modulation by PNU120596 promotes enhanced calcium entry through the open $\alpha 7$ channel and the activation of RyR-associated CICR. Direct interaction between the $\alpha 7 \mathrm{nAChR}$ and G $\alpha \mathrm{q}$ activates PLC, resulting in $\mathrm{IP}_{3} \mathrm{R}$-mediated IICR, which can be further augmented by elevated local calcium acting on PLC as well as $\mathrm{IP}_{3} R$. (B) Intracellular calcium signaling by the $\alpha 7 \mathrm{nAChR}$ is differentially regulated by the binding of orthosteric and allosteric compounds.

These studies also show an effect of PNU120596 on intracellular calcium signaling at the growth cone of PC12 cells that is corroborated by a new computational model of $\alpha 7$ $\mathrm{nAChR}$ calcium signaling through the ER. This computational model is established on published single channel recording for the $\alpha 7$ receptor in mammalian cells (McCormack et al., 2010; Corradi and Bouzat, 2016). The model accurately predicts intracellular calcium transients with similar time and amplitude properties as our experimental measures. The model extends our experimental data by showing that an ability of the $\alpha 7$ receptor to regulate CICR (as well as IICR) depends on colocalization between $\alpha 7 \mathrm{nAChRs}$ and Ry as well as $\mathrm{IP}_{3}$ receptors in regions where the plasma membrane and the ER are in close proximity. At such sites, PNU120596 modulation is associated with enhanced time in the open channel state and decreased time in the desensitized state; this is matched by greater peak current and open probability (21-fold) within the model similar to experimental results. PNU120596 modulation of the $\alpha 7$ channel drives strong calcium influx that is critical for activating nearby RyRs through CICR. Earlier studies in neurons and brain slices support this idea by showing that $\alpha 7$ receptors localize to ER-rich cellular domains and can directly regulate calcium release from the ER, which is essential for their function at neuronal synapsis (Zhong et al., 2013). Experiments and computational studies provided 
in this study elucidate a mechanism of $\alpha 7 / \mathrm{ER}$ coupling that can guide future studies on the effects and therapeutic potential of $\alpha 7$-targeting compounds.

Taken together, our findings support the notion that PAMs act at the $\alpha 7 \mathrm{nAChR}$ site through enhanced ionotropic flux through the open channel, which in turn activates CICR, leading to calcium signal transduction. We show that this effect strongly depends on spatial and functional coupling between the $\alpha 7$ receptor and the ER within the cell. In some cells (such as immune cells), however, it is possible that PAM modulation of the $\alpha 7 \mathrm{nAChR}$ is less paired to CICR especially if the $\alpha 7$ receptor is not in the vicinity of the ER. In such a case, it is plausible that a PAM such as PNU120596 operates via enhanced $G$ protein-mediated metabotropic signaling and through a nonconducting $\alpha 7$ state, which has been suggested (Bouzat et al., 2017). In fact, our study supports the role of PNU120596 in augmented metabotropic G protein signaling by the $\alpha 7$ receptor through enhanced PLC activity and $\mathrm{IP}_{3} \mathrm{R}$ driven IICR (Fig. 8). PNU120596-mediated increases in ionotropic-driven CICR within cells do not occlude metabotropic coupling, which appears to also increase in the presence of this compound. In fact, PAM-associated CICR leading to elevated calcium within the $\alpha 7 / \mathrm{ER}$ microdomain may support metabotropic $G$ protein signaling through increased PLC activation and $\mathrm{IP}_{3} \mathrm{R}$ conductance, because both molecules are positively driven by calcium ions. Based on this study, it is thus important to consider ionotropic and metabotropic $\alpha 7$ $\mathrm{nAChR}$ modes when assessing the effectiveness and function of an allosteric modulator (Kabbani and Nichols, 2018). In neurons, where $\alpha 7 \mathrm{nAChRs}$ are regulators of synaptic activity that underlies learning and memory through various forms of intracellular calcium signaling (Ge and Dani, 2005; Shen and Yakel, 2009; Gomez-Varela and Berg, 2013), the mechanisms of pharmacological neuromodulation maybe translate to specific measured outcomes in enhanced cognition and learning (Deutsch et al., 2013; Bouzat et al., 2017).

\section{Authorship Contributions}

Participated in research design: King, Ullah, Jafri, Kabbani.

Conducted experiments: King, Bak, Ullah.

Contributed new reagents or analytic tools: Ullah, Jafri.

Performed data analysis: King, Ullah, Jafri, Kabbani.

Wrote or contributed to the writing of the manuscript: King, Ullah, Jafri, Kabbani.

\section{References}

Akerboom J, Chen T-W, Wardill TJ, Tian L, Marvin JS, Mutlu S, Calderón NC, Esposti F, Borghuis BG, Sun XR, et al. (2012) Optimization of a GCaMP calcium indicator for neural activity imaging. J Neurosci 32:13819-13840.

Alkondon M, Pereira EF, Cortes WS, Maelicke A, and Albuquerque EX (1997) Choline is a selective agonist of alpha7 nicotinic acetylcholine receptors in the rat brain neurons. Eur J Neurosci 9:2734-2742.

Andersen ND, Nielsen BE, Corradi J, Tolosa MF, Feuerbach D, Arias HR, and Bouzat C (2016) Exploring the positive allosteric modulation of human $\alpha 7$ nicotinic receptors from a single-channel perspective. Neuropharmacology 107: 189-200.

Bencherif M, Lippiello PM, Lucas R, and Marrero MB (2011) Alpha7 nicotinic receptors as novel therapeutic targets for inflammation-based diseases. Cell Mol Life Sci 68:931-949.

Bocquet N, Nury H, Baaden M, Le Poupon C, Changeux J-P, Delarue M, and Corringer P-J (2009) X-ray structure of a pentameric ligand-gated ion channel in an apparently open conformation. Nature 457:111-114

Bouzat C, Lasala M, Nielsen BE, Corradi J, and Esandi MDC (2017) Molecular function of $\alpha 7$ nicotinic receptors as drug targets. J Physiol DOI: 10.1113/JP275101 [published ahead of print].

Campbell NR, Fernandes CC, Halff AW, and Berg DK (2010) Endogenous signaling through alpha7-containing nicotinic receptors promotes maturation and in tegration of adult-born neurons in the hippocampus. J Neurosci 30:8734-8744.

Chan J and Quik M (1993) A role for the nicotinic $\alpha$-bungarotoxin receptor in neurite outgrowth in PC12 cells. Neuroscience 56:441-451.
Changeux J-P (2010) Nicotine addiction and nicotinic receptors: lessons from genetically modified mice. Nat Rev Neurosci 11:389-401.

Cheng Q and Yakel JL (2015) Activation of $\alpha 7$ nicotinic acetylcholine receptors in creases intracellular cAMP levels via activation of AC1 in hippocampal neurons. Neuropharmacology 95:405-414.

Chisari M, Saini DK, Cho J-H, Kalyanaraman V, and Gautam N (2009) G protein subunit dissociation and translocation regulate cellular response to receptor stimulation. PLoS One 4:e7797.

Colón-Sáez JO and Yakel JL (2014) A mutation in the extracellular domain of the $\alpha 7$ nAChR reduces calcium permeability. Pflugers Arch 466:1571-1579.

Corradi J and Bouzat C (2016) Understanding the bases of function and modulation of $\alpha 7$ nicotinic receptors: implications for drug discovery. Mol Pharmacol 90: $288-299$.

Deutsch SI, Schwartz BL, Schooler NR, Brown CH, Rosse RB, and Rosse SM (2013) Targeting alpha-7 nicotinic neurotransmission in schizophrenia: a novel agonist strategy. Schizophr Res 148:138-144

Freitas K, Carroll FI, and Damaj MI (2013a) The antinociceptive effects of nicotinic receptors $\alpha 7$-positive allosteric modulators in murine acute and tonic pain models $J$ Pharmacol Exp Ther 344:264-275.

Freitas K, Ghosh S, Ivy Carroll F, Lichtman AH, and Imad Damaj M (2013b) Effects of $\alpha 7$ positive allosteric modulators in murine inflammatory and chronic neuropathic pain models. Neuropharmacology 65:156-164.

Ge S and Dani JA (2005) Nicotinic acetylcholine receptors at glutamate synapses facilitate long-term depression or potentiation. J Neurosci 25:6084-6091.

Gomez-Varela D and Berg DK (2013) Lateral mobility of presynaptic $\alpha 7$-containing nicotinic receptors and its relevance for glutamate release. $J$ Neurosci 33 17062-17071.

Grønlien JH, Håkerud M, Ween H, Thorin-Hagene K, Briggs CA, Gopalakrishnan $\mathrm{M}$, and Malysz J (2007) Distinct profiles of alpha7 $\mathrm{nAChR}$ positive allosteric modulation revealed by structurally diverse chemotypes. Mol Pharmacol 72: 715-724.

Gu Z and Yakel JL (2011) Timing-dependent septal cholinergic induction of dynamic hippocampal synaptic plasticity. Neuron 71:155-165.

Guerra-Álvarez M, Moreno-Ortega AJ, Navarro E, Fernández-Morales JC, Egea J, López MG, and Cano-Abad MF (2015) Positive allosteric modulation of alpha-7 nicotinic receptors promotes cell death by inducing $\mathrm{Ca}(2+)$ release from the endoplasmic reticulum. $J$ Neurochem 133:309-319.

Halff AW, Gómez-Varela D, John D, and Berg DK (2014) A novel mechanism for nicotinic potentiation of glutamatergic synapses. J Neurosci 34:2051-2064.

Hashimoto K (2015) Targeting of $\alpha 7$ nicotinic acetylcholine receptors in the treatment of schizophrenia and the use of auditory sensory gating as a translational biomarker. Curr Pharm Des 21:3797-3806.

He Y, Francis F, Myers KA, Yu W, Black MM, and Baas PW (2005) Role of cytoplasmic dynein in the axonal transport of microtubules and neurofilaments. J Cell Biol 168:697-703.

Jones S and Yakel JL (1997) Functional nicotinic ACh receptors on interneurones in the rat hippocampus. J Physiol 504:603-610.

Kabbani N and Nichols RA (2018) Beyond the channel: metabotropic signaling by nicotinic receptors. Trends Pharmacol Sci 39:354-366.

King JR, Gillevet TC, and Kabbani N (2017) A G protein-coupled $\alpha 7$ nicotinic receptor regulates signaling and TNF- $\alpha$ release in microglia. FEBS Open Bio 7 1350-1361.

King JR and Kabbani N (2016) Alpha 7 nicotinic receptor coupling to heterotrimeric $\mathrm{G}$ proteins modulates RhoA activation, cytoskeletal motility, and structural growth. J Neurochem 138:532-545.

King JR, Nordman JC, Bridges SP, Lin M-K, and Kabbani N (2015) Identification and characterization of a $\mathrm{G}$ protein-binding cluster in $\alpha 7$ nicotinic acetylcholine receptors. J Biol Chem 290:20060-20070.

Le Novère N, Corringer P-J, and Changeux J-P (2002) The diversity of subunit composition in nAChRs: evolutionary origins, physiologic and pharmacologic consequences. J Neurobiol 53:447-456.

Liu Qs and Berg DK (1999) Actin filaments and the opposing actions of CaM kinase II and calcineurin in regulating alpha7-containing nicotinic receptors on chick ciliary ganglion neurons. J Neurosci 19:10280-10288.

McCormack TJ, Melis C, Colón J, Gay EA, Mike A, Karoly R, Lamb PW, Molteni C, and Yakel JL (2010) Rapid desensitization of the rat $\alpha 7 \mathrm{nAChR}$ is facilitated by the presence of a proline residue in the outer $\beta$-sheet. $J$ Physiol 588:4415-4429.

McLean SL, Idris NF, Grayson B, Gendle DF, Mackie C, Lesage AS, Pemberton DJ, and Neill JC (2012) PNU-120596, a positive allosteric modulator of $\alpha 7$ nicotinic acetylcholine receptors, reverses a sub-chronic phencyclidine-induced cognitive deficit in the attentional set-shifting task in female rats. $J$ Psychopharmacol 26 : $1265-1270$.

Nordman JC and Kabbani N (2012) An interaction between $\alpha 7$ nicotinic receptors and a G-protein pathway complex regulates neurite growth in neural cells. $J$ Cell Sci 125:5502-5513.

Nordman JC and Kabbani N (2014) Microtubule dynamics at the growth cone are mediated by $\alpha 7$ nicotinic receptor activation of a G $\alpha$ q and IP3 receptor pathway. FASEB J 28:2995-3006.

Papke RL, Bencherif M, and Lippiello P (1996) An evaluation of neuronal nicotinic acetylcholine receptor activation by quaternary nitrogen compounds indicates that choline is selective for the alpha 7 subtype. Neurosci Lett 213:201-204.

Rogers SW, Mandelzys A, Deneris ES, Cooper E, and Heinemann S (1992) The expression of nicotinic acetylcholine receptors by PC12 cells treated with NGF. $J$ Neurosci 12:4611-4623.

Santos MdeS, Naal RM, Baird B, and Holowka D (2013) Inhibitors of PI(4,5)P2 synthesis reveal dynamic regulation of $\mathrm{IgE}$ receptor signaling by phosphoinositides in RBL mast cells. Mol Pharmacol 83:793-804.

Saragoza PA, Modir JG, Goel N, French KL, Li L, Nowak MW, and Stitzel JA (2003) Identification of an alternatively processed nicotinic receptor alpha7 subunit RNA in mouse brain. Brain Res Mol Brain Res 117:15-26. 
Séguéla P, Wadiche J, Dineley-Miller K, Dani JA, and Patrick JW (1993) Molecular cloning, functional properties, and distribution of rat brain alpha 7: a nicotinic cation channel highly permeable to calcium. J Neurosci 13:596-604.

Shen JX and Yakel JL (2009) Nicotinic acetylcholine receptor-mediated calcium signaling in the nervous system. Acta Pharmacol Sin 30:673-680.

Shytle RD, Mori T, Townsend K, Vendrame M, Sun N, Zeng J, Ehrhart J, Silver AA Sanberg PR, and Tan J (2004) Cholinergic modulation of microglial activation by alpha 7 nicotinic receptors. J Neurochem 89:337-343.

Ullah G and Ullah A (2016) Mode switching of inositol 1,4,5-trisphosphate receptor channel shapes the spatiotemporal scales of $\mathrm{Ca}^{2+}$ signals. J Biol Phys 42:507-524.

Uteshev VV (2014) The therapeutic promise of positive allosteric modulation of nicotinic receptors. Eur J Pharmacol 727:181-185.

Verkhratsky A (2002) The endoplasmic reticulum and neuronal calcium signalling. Cell Calcium 32:393-404.

Wang H, Yu M, Ochani M, Amella CA, Tanovic M, Susarla S, Li JH, Wang H, Yang H, Ulloa L, et al. (2003) Nicotinic acetylcholine receptor $\alpha 7$ subunit is an essential regulator of inflammation. Nature 421:384-388.
Williams DK, Peng C, Kimbrell MR, and Papke RL (2012) Intrinsically low open probability of $\alpha 7$ nicotinic acetylcholine receptors can be overcome by positive allosteric modulation and serum factors leading to the generation of excitotoxic currents at physiological temperatures. Mol Pharmacol 82:746-759.

Williams GSB, Chikando AC, Tuan H-TM, Sobie EA, Lederer WJ, and Jafri MS (2011) Dynamics of calcium sparks and calcium leak in the heart. Biophys $J$ 101: 1287-1296.

Zhang Q, Du Y, Zhang J, Xu X, Xue F, Guo C, Huang Y, Lukas RJ, and Chang Y (2015) Functional impact of 14 single nucleotide polymorphisms causing missense mutations of human $\alpha 7$ nicotinic receptor. PLoS One 10:e0137588.

Zhong C, Talmage DA, and Role LW (2013) Nicotine elicits prolonged calcium signaling along ventral hippocampal axons. PLoS One 8:e82719.

Address correspondence to: Dr. Nadine Kabbani, George Mason University, 4400 University Drive, Fairfax, VA 22030. E-mail: nkabbani@gmu.edu 